\title{
Diaphragmatic excursion correlates with exercise capacity and dynamic hyperinflation in COPD patients
}

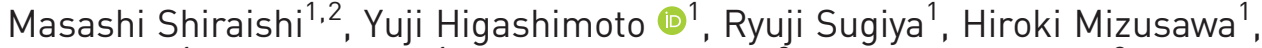 \\ Yu Takeda ${ }^{1}$, Shuhei Fujita ${ }^{1}$, Osamu Nishiyama², Shintarou Kudo $\mathbb{1}^{3}$, \\ Tamotsu Kimura ${ }^{1}$, Yasutaka Chiba ${ }^{4}$, Kanji Fukuda ${ }^{1}$ and Yuji Tohda ${ }^{2}$
}

Affiliations: 'Dept of Rehabilitation Medicine, Kindai University School of Medicine, Osaka, Japan. ${ }^{2}$ Dept of Respiratory Medicine and Allergology, Kindai University School of Medicine, Osaka, Japan. ${ }^{3}$ Inclusive Medical Science Research Institute, Morinomiya University of Health Sciences, Osaka, Japan. ${ }^{4}$ Division of Biostatistics, Clinical Research Center, Kindai University School of Medicine, Osaka, Japan.

Correspondence: Masashi Shiraishi, Rehabilitation, Kindai University Hospital, 377-2 Onohigashi, Osakasayama-city, 5898511, Japan. E-mail: masashi-shiraishi@med.kindai.ac.jp

\section{ABSTRACT}

Background: Although the pathophysiological mechanisms involved in the development of dyspnoea and poor exercise tolerance in patients with COPD are complex, dynamic lung hyperinflation (DLH) plays a central role. Diaphragmatic excursions can be measured by ultrasonography (US) with high intra- and interobserver reliability. The objective of this study was to evaluate the effect of diaphragmatic excursions as assessed by US on exercise tolerance and DLH in patients with COPD.

Methods: Patients with COPD $(n=20)$ and age-matched control subjects $(n=20)$ underwent US, which was used to determine the maximum level of diaphragmatic excursion ( $\mathrm{DE}_{\max }$ ). Ventilation parameters, including the change in inspiratory capacity $(\Delta \mathrm{IC})$, were measured in the subjects during cardiopulmonary exercise testing (CPET). We examined the correlations between $\mathrm{DE}_{\max }$ and the ventilation parameters.

Results: The $\mathrm{DE}_{\max }$ of patients with $\mathrm{COPD}$ was significantly lower than that of the controls (45.0 $\pm 12.8 \mathrm{~mm}$ versus $64.6 \pm 6.3 \mathrm{~mm}$, respectively; $\mathrm{p}<0.01$ ). The perception of peak dyspnoea (Borg scale) was significantly negatively correlated with $\mathrm{DE}_{\max }$ in patients with COPD. During CPET, oxygen uptake/ weight $\left(V_{\mathrm{O}_{2}}^{\prime} / W\right)$ and minute ventilation $\left(V_{\mathrm{E}}^{\prime}\right)$ were significantly positively correlated with $\mathrm{DE}_{\max }$, while $V_{\mathrm{E}}^{\prime} / V^{\prime} \mathrm{O}_{2}$ and $V_{\mathrm{E}}^{\prime}$ /carbon dioxide output $\left(V_{\mathrm{CO}_{2}}^{\prime}\right)$ were significantly negatively correlated with $\mathrm{DE}_{\max }$ in patients with COPD. $\mathrm{DE}_{\max }$ was also significantly positively correlated with $\triangle \mathrm{IC}$, reflecting $\mathrm{DLH}$, and with $V^{\prime}{ }_{\mathrm{O}_{2}} / W$, reflecting exercise capacity.

Conclusion: Reduced mobility of the diaphragm was related to decreased exercise capacity and increased dyspnoea due to dynamic lung hyperinflation in COPD patients.

@ERSpublications

Reduced diaphragmatic excursion, as measured on ultrasound images, might predict decreased exercise capacity and increased dyspnoea due to dynamic lung hyperinflation in COPD patients https://bit.ly/3jkERxZ

Cite this article as: Shiraishi M, Higashimoto Y, Sugiya R, et al. Diaphragmatic excursion correlates with exercise capacity and dynamic hyperinflation in COPD patients. ERJ Open Res 2020; 6: 005892020 [https://doi.org/10.1183/23120541.00589-2020].

This article has supplementary material available from openres.ersjournals.com.

Received: 27 April 2020 | Accepted after revision: 18 Sept 2020

Copyright $\odot$ ERS 2020. This article is open access and distributed under the terms of the Creative Commons Attribution Non-Commercial Licence 4.0. 


\section{Introduction}

COPD is a progressive disease characterised by minimally reversible airflow limitation. The main feature of COPD is the inability of patients to cope with their activities of daily life because of shortness of breath. Although the pathophysiological mechanisms involved in the development of dyspnoea and poor exercise tolerance in patients with COPD are complex, dynamic lung hyperinflation (DLH) plays a central role [1]. DLH has a static component, which is due to the destruction of pulmonary parenchyma and loss of elastic recoil by the lung; and a dynamic component, which occurs when patients with COPD breathe in before achieving a complete exhalation. Airflow limitation and DLH are the main causative factors of the dyspnoea occurring in COPD patients. DLH is tightly linked to dyspnoea and exercise tolerance. In the DLH of COPD, the residual volume increases because of airflow limitation related to exertion. DLH is expressed as decreased inspiratory capacity (IC) and increased functional residual capacity (FRC) due to a continually increasing end-expiratory lung volume $[2,3]$. The major consequence of DLH is an increased ventilatory workload and decreased pressure-generating capacity by the inspiratory muscles, despite compensatory mechanisms [4].

The diaphragm is the main muscle employed for respiration. Patients with emphysema or COPD manifest major changes in the mass, thickness, and area of the diaphragm. Diaphragmatic contractions produce muscle shortening and thickening. Ultrasonography has been recently proposed for use in assessing both diaphragmatic excursions [5-7] and diaphragmatic thickness at different lung volumes [8]. The association between thickening of the diaphragm and diaphragmatic effort, however, is tenuous; ultrasonography measurements of diaphragmatic thickness explain only one-third (or less) of the variability in inspiratory efforts $[9,10]$. On the other hand, ultrasonographic assessment of excursions of the right diaphragm shows high intra- and interobserver reliability [11]. Reduced movements of the diaphragm are a major risk factor for increased mortality in patients with COPD [12]. However, the relationship between diaphragmatic mobility and DLH remains unclear in patients with COPD. The primary purpose of this study was to evaluate the difference between the diaphragmatic excursions of patients with COPD versus control participants. The secondary purpose was to evaluate the effects of decreased diaphragmatic excursion on exercise tolerance and DLH in COPD patients.

\section{Materials and methods}

\section{Study design and participants}

This was a single-centre, observational, case-control, cross-sectional study. It was approved by the Committee for Ethics at Kindai University School of Medicine (no. 31-086), and all participants provided written informed consent. The participants were 20 patients with clinically stable COPD who visited the Department of Respiratory Medicine and Allergology at Kindai University Hospital between April 2019 and August 2019. The exclusion criteria included unstable medical conditions that could cause or contribute to breathlessness (i.e. metabolic, cardiovascular, or other respiratory diseases) or any other disorders that could interfere with exercise testing, such as neuromuscular diseases or musculoskeletal problems. We also recruited 20 age-matched volunteers who did not have any detectable chronic condition, including pulmonary or cardiovascular disease. Based on preliminary studies in healthy participants $(n=6)$ and COPD patients $(n=5)$, the average extent of diaphragmatic excursion in the healthy participants and COPD patients was $72.0 \mathrm{~mm}(\mathrm{SD}=10.1)$ and $50.9 \mathrm{~mm}(\mathrm{SD}=9.4)$ respectively. We assumed the difference between the population means of the two groups as $10 \mathrm{~mm}$ with a SD of $10.0 \mathrm{~mm}$ With these values, the required number of cases would be 34 (17 participants in each group) based on the t-test, which was used to assess the difference between the maximum diaphragmatic excursions $\left(\mathrm{DE}_{\max }\right)$ of the two groups, with a significance level of $5 \%$ (both sides) and a study power of $80 \%$. With an accounting of participants leaving the study, the target number of participants was set at 40 (20 in each group).

\section{Measurements}

All participants underwent ultrasonography (Xario 200; Toshiba, Tokyo, Japan) for measurement of their $\mathrm{DE}_{\max }$. Excursions of the right hemidiaphragm were measured by a convex $3.5-\mathrm{MHz}$ probe according to the techniques of Testa et al. [7]. The liver on the left was used as an acoustic window (figure 1). The M-mode cursor was rotated and placed on the axis of diaphragmatic displacement on the stored image, and displacement measurements were conducted. Measurements were performed during each of three deep breaths, and the $\mathrm{DE}_{\max }$ was measured (figure 1c).

All participants underwent symptom-limited cardiopulmonary exercise testing (CPET) on a bicycle ergometer, according to the Ramp $10 \mathrm{~W}$ protocol (load increase of $10 \mathrm{~W} \cdot \mathrm{min}^{-1}, 1 \mathrm{~W}$ per $6 \mathrm{~s}$ ). The 10-point Borg scale was used to assess the intensity of dyspnoea, and leg fatigue was determined at 1-min intervals during both the exercise and resting period [13]. The analysis included the following: intensity of exercise (workload in watts), peak oxygen consumption (peak $V_{\mathrm{O}_{2}}^{\prime} / W$ ), ventilation equivalents for oxygen $\left(V_{\mathrm{E}}^{\prime} / V_{\mathrm{O}_{2}}^{\prime}\right)$ and carbon dioxide $\left(V_{\mathrm{E}}^{\prime} / V_{\mathrm{CO}_{2}}^{\prime}\right)$. IC manoeuvres were performed at rest, and at 1-min intervals 
a)

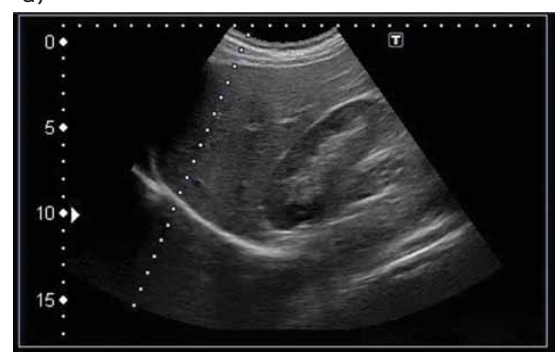

b)

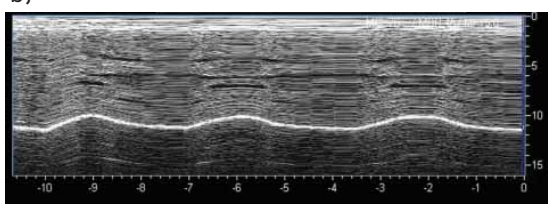

c)

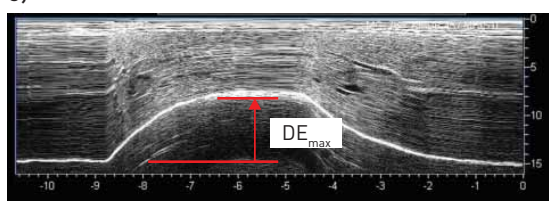

FIGURE 1 Representative image of right diaphragm. The probe was positioned below the right costal margin between the midclavicular and anterior axillary lines. a) Two-dimensional ultrasonographic image of the right hemidiaphragm (B-mode). Diaphragmatic movements were recorded in b) $M$-mode during quiet breathing and c) during deep breathing ( $\left.D E_{\max }\right)$. $D E_{\max }$ : maximum diaphragmatic excursion.

and peak exercise. We measured the change in inspiratory capacity $\left(\Delta \mathrm{IC}=\mathrm{IC}_{\text {lowest }}-\mathrm{IC}_{\text {baseline }}\right)$ during exercise as a surrogate marker of DLH $[14,15]$.

Spirometry (CHESTAC-800; Chest, Tokyo, Japan) was performed according to the 2019 American Thoracic Society recommendations [16] for measuring forced vital capacity (FVC), forced expiratory volume in $1 \mathrm{~s}\left(\mathrm{FEV}_{1}\right)$, and IC. Respiratory muscle strength was assessed by measuring the maximum inspiratory pressure (MIP) generated against an occluded airway at residual volume [17] (SP-370; Fukuda Denshi, Tokyo, Japan). Quadriceps muscle strength (QMS) was measured by a hand-held dynamometer ((HHD) $\mu$ TasF-1, Anima Corp, Tokyo).

\section{Statistical analysis}

All results are expressed as mean $\pm \mathrm{SD}$. The t-test was used to compare data from the COPD patients with data from the healthy controls. Inter-rater reliability (reproducibility) of the mean values of three $\mathrm{DE}_{\max }$ measurements for each patient was assessed by estimating intraclass correlation coefficients (ICCs). Two ICC forms were estimated: ICC $(1,1)$ and $\operatorname{ICC}(1, \mathrm{k})$, representing values calculated from a single measurement and from an average of $\mathrm{k}$ repeated measures, respectively. In this study, $\mathrm{k}=3$. The relationship between $\mathrm{DE}_{\max }$ and the parameters of lung function $\left(V_{\mathrm{O}_{2}}^{\prime} / W, V_{\mathrm{E}}^{\prime} / V_{\mathrm{O}_{2}}^{\prime}, V_{\mathrm{E}}^{\prime} / V_{\mathrm{CO}_{2}}^{\prime}, \Delta \mathrm{IC}\right.$, and MIP) and muscle strength of the lower extremities was evaluated by calculating Pearson correlation coefficients, where $\mathrm{p}<0.05$ was deemed to be significant. We performed a least squares regression analysis to compute the final predictive model for $V_{\mathrm{O}_{2}}^{\prime} / W$. Statistical analysis was performed by IBM SPSS statistics software, version 22 (IBM SPSS, Armonk, NY, USA).

\section{Results}

Table 1 summarises the clinical characteristics of patients with COPD and the control participants. The $\mathrm{FEV}_{1}$ of COPD patients was significantly lower than the $\mathrm{FEV}_{1}$ of the controls $(\mathrm{p}<0.01)$, whereas the difference between the FVC values of the two groups was not significant. The intensity of peak dyspnoea (Borg scale) in COPD patients was significantly larger than that in the controls $(\mathrm{p}<0.01)$. The peak $V^{\prime} \mathrm{O}_{2} / W$ value was significantly lower in COPD patients than in the controls $(\mathrm{p}<0.01)$. The $V_{\mathrm{E}}^{\prime} / V_{\mathrm{O}_{2}}^{\prime}$ was significantly higher in COPD patients than in the controls $(\mathrm{p}<001)$. The decrease in IC during CPET was significantly greater in COPD patients than in the controls $(\mathrm{p}<0.01)$. The MIP was significantly lower in COPD patients than in the controls $(\mathrm{p}<0.01)$. The intra-rater reliability of $\mathrm{DE}_{\text {max }}$ measurements by ultrasonography was as follows: ICC $(1,1)=0.89$, ICC $(1, \mathrm{k})=0.91$, indicating good reproducibility (tables 1S and $2 \mathrm{~S})$. The $\mathrm{DE}_{\max }$ of COPD patients was significantly lower than that of the controls $(45.0 \pm 12.8 \mathrm{~mm}$ versus $64.6 \pm 6.3 \mathrm{~mm}$, respectively; $\mathrm{p}<0.01$ ) (figure 2). Peak dyspnoea perception (Borg scale) was negatively correlated with the $\mathrm{DE}_{\max }$ of patients with COPD (table 2, $\mathrm{p}<001$ ). Peak mBorg scale dyspnoea was negatively correlated with $\triangle \mathrm{IC}(\mathrm{r}=-0.61, \mathrm{p}<0.05)$. Regarding lung function parameters, $\mathrm{VC}, \mathrm{IC}, \mathrm{FVC}$, and $\mathrm{FEV}_{1}$ were significantly positively correlated with the $\mathrm{DE}_{\max }$ of patients with COPD. $\mathrm{DE}_{\max }$ was positively correlated with MIP $(\mathrm{p}<001)$. $\triangle \mathrm{IC}$, which reflects DLH, was significantly positively correlated with DEmax in COPD patients but not in control participants (figure 3 and table 2). IC decreased during exercise, and $\triangle \mathrm{IC}$ was negative in all of the COPD patients, while IC increased during exercise and $\triangle \mathrm{IC}$ was non-negative in some of control participants. Regarding ventilation parameters during CPET, $V_{\mathrm{O}_{2}}^{\prime} / W$ and $V_{\mathrm{E}}^{\prime}$ were significantly positively correlated with $\mathrm{DE}$ max , while $V_{\mathrm{E}}^{\prime} / V_{\mathrm{O}_{2}}^{\prime}$ and $V_{\mathrm{E}}^{\prime} / V^{\prime} \mathrm{CO}_{2}$ were significantly negatively correlated with $\mathrm{DE}_{\max }$ in both the control participants and COPD patients (table 2 and figure 4). Multiple regression analysis was performed for $V_{\mathrm{O}_{2}}^{\prime} / W$ as the dependent variable and $\mathrm{DE}_{\max }$ and $\% \mathrm{FEV}_{1}$ as the independent variables. Both $\mathrm{DE}_{\max }$ and $\% \mathrm{FEV}_{1}$ were significantly correlated with $V_{\mathrm{O}_{2}}^{\prime} / W$. $\mathrm{DE}_{\max }$ was found to be the most independent explanatory variable $\left(\mathrm{R}^{2}=0.79, \mathrm{~F}=29.4,95 \% \mathrm{CI} 0.18\right.$ to 0.37 , $\mathrm{p}<0.0001$, table 3S). 


\section{TABLE 1 Characteristics of study participants}

\begin{tabular}{|c|c|c|c|}
\hline & $\operatorname{COPD}(n=20)$ & Control $(n=20)$ & p-value \\
\hline Male/female & $17 / 3$ & $17 / 3$ & \\
\hline Age years & $76.8 \pm 3.6$ & $76.4 \pm 5.1$ & 0.80 \\
\hline Body mass index $\mathrm{kg} \cdot \mathrm{m}^{-2}$ & $22.9 \pm 3.3$ & $23.9 \pm 2.3$ & 0.65 \\
\hline QMS Kgf $\cdot \mathbf{k g}^{-1}$ & $0.57 \pm 0.14$ & $0.64 \pm 0.12$ & 0.36 \\
\hline GOLD I/II/III & $2 / 10 / 8$ & ND & \\
\hline mMRC $0 / 1 / 2 / 3 / 4$ & $0 / 13 / 6 / 1 / 0$ & ND & \\
\hline \multicolumn{4}{|l|}{ Pulmonary function } \\
\hline $\mathrm{FEV}_{1} \mathrm{~L}$ & $1.58 \pm 0.45$ & $2.44 \pm 0.39$ & $<0.01$ \\
\hline$\%$ predicted & $53.9 \pm 19.4$ & $103.1 \pm 14.2$ & $<0.01$ \\
\hline FVC L & $3.12 \pm 0.89$ & $3.24 \pm 0.51$ & 0.89 \\
\hline$\%$ predicted & $93.4 \pm 26.9$ & $105.1 \pm 13.4$ & 0.25 \\
\hline MIP $\mathrm{cmH}_{2} \mathrm{O}$ & $59.4 \pm 19.4$ & $84.6 \pm 21.9$ & $<0.01$ \\
\hline$\%$ predicted & $81.1 \pm 31.1$ & $119.2 \pm 28.4$ & $<0.01$ \\
\hline \multicolumn{4}{|l|}{ Peak exercise measurements } \\
\hline Peak load W & $67 \pm 20$ & $115 \pm 22$ & $<0.01$ \\
\hline$V_{E}^{\prime} L \cdot \min ^{-1}$ & $42.5 \pm 12.1$ & $52.4 \pm 11.7$ & $<0.05$ \\
\hline Peak $V_{\mathrm{O}_{2}} / W \mathrm{~mL} \cdot \mathrm{min}^{-1} \cdot \mathrm{kg}^{-1}$ & $12.4 \pm 2.9$ & $20.2 \pm 1.7$ & $<0.01$ \\
\hline$V_{E}^{\prime} / V_{\mathrm{O}_{2}}^{\prime} \mathrm{mL} \cdot \mathrm{mL}^{-1}$ & $46.9 \pm 8.5$ & $29.3 \pm 2.7$ & $<0.01$ \\
\hline$\Delta \mathrm{IC}$ from rest $\mathrm{L}$ & $-0.40 \pm 0.24$ & $0.05 \pm 0.25$ & $<0.01$ \\
\hline mBorg scale dyspnoea & $5 \pm 1$ & $2 \pm 2$ & $<0.01$ \\
\hline mBorg scale leg fatigue & $5 \pm 1$ & $4 \pm 2$ & 0.15 \\
\hline \multicolumn{4}{|c|}{$\begin{array}{l}\text { Data are presented as mean } \pm \text { SD unless otherwise stated. QMS: quadriceps muscle strength; GOLD: } \\
\text { Global Initiative for Chronic Obstructive Lung Disease; mMRC: modified Medical Research Council } \\
\text { dyspnoea scale; FEV } V_{1} \text { : forced expiratory volume in } 1 \mathrm{~S} ; \mathrm{FVC} \text { : forced vital capacity; MIP: maximum } \\
\text { inspiratory pressure; ND: not done in the control group; } V_{\mathrm{O}_{2}}^{\prime} \text { oxygen uptake; } V^{\prime}{ }_{\mathrm{O}_{2}} / W \text { : oxygen uptake/weight; } \\
V^{\prime}{ }_{\mathrm{E}} \text { : minute ventilation; IC: inspiratory capacity; MIP: maximum inspiratory pressure; mBorg: modified } \\
\text { Borg scale. }\end{array}$} \\
\hline
\end{tabular}

\section{Discussion}

The $\mathrm{DE}_{\max }$ of COPD patients was significantly lower than that of control participants. $\mathrm{DE}_{\max }$ was associated with exercise tolerance in both the healthy participants and COPD patients. Ultrasonographic assessment of diaphragmatic function has been widely and successfully used to detect the presence of diaphragmatic dysfunction as a postsurgical complication [18], to identify ventilator-induced diaphragmatic injury [19], to evaluate movement of the diaphragmatic dome [20] during spontaneous breathing in weaning trials [21], to quantify the work of breathing [9], to titrate ventilatory support $[9,10,21]$, and to predict the success of extubation [22]. Ultrasonography has been studied in COPD patients and has shown that diaphragmatic mobility can affect COPD patients' dyspnoea and the 6-min walk distance [23]. Ultrasonography has also been used to identify diaphragmatic dysfunction [24]. However, to date, the relationships between diaphragmatic mobility and DLH and exercise tolerance in patients with COPD remain unknown. This study shows that decreased diaphragmatic mobility is associated with decreased

FIGURE 2 Maximum diaphragmatic exertion during deep breathing $\left(D E_{\max }\right)$ in COPD patients $(n=20)$ and control participants $(n=20)$. $D E_{\max }$ in COPD patients was significantly smaller than that in control participants. ${ }^{* *}: p<0.01$.

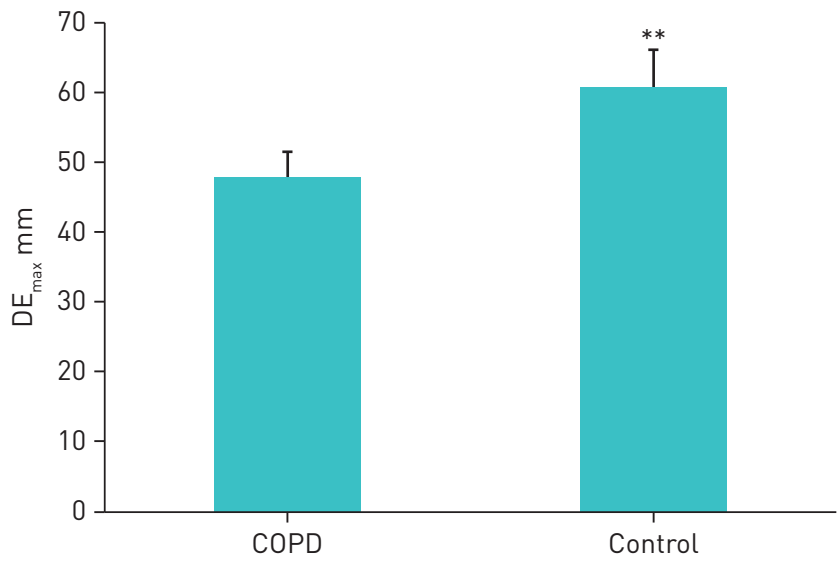




\begin{tabular}{|c|c|c|c|c|}
\hline \multirow[t]{2}{*}{ Independent variable } & \multicolumn{2}{|l|}{ COPD $(n=20)$} & \multicolumn{2}{|c|}{ Control $(n=20)$} \\
\hline & $\begin{array}{l}\text { Pearson correlation } \\
\text { coefficient }\end{array}$ & p-value & $\begin{array}{l}\text { Pearson correlation } \\
\text { coefficient }\end{array}$ & p-value \\
\hline Age & 0.19 & 0.43 & 0.19 & 0.43 \\
\hline BMI & 0.03 & 0.91 & -0.14 & 0.53 \\
\hline QMS & 0.39 & 0.09 & 0.15 & 0.11 \\
\hline \multicolumn{5}{|l|}{ Resting measurements } \\
\hline IC & 0.6 & $<0.01$ & 0.2 & 0.38 \\
\hline FVC & 0.4 & $<0.05$ & -0.06 & 0.79 \\
\hline$\%$ predicted & 0.32 & 0.16 & -0.35 & 1.29 \\
\hline $\mathrm{FEV}_{1}$ & 0.52 & $<0.05$ & -0.09 & 0.71 \\
\hline$\%$ predicted & 0.37 & 0.12 & -0.33 & 0.19 \\
\hline MIP & 0.65 & $<0.01$ & 0.24 & 0.29 \\
\hline$\%$ predicted & 0.68 & $<0.01$ & 0.09 & 0.29 \\
\hline \multicolumn{5}{|l|}{$\begin{array}{l}\text { Peak exercise } \\
\text { measurements }\end{array}$} \\
\hline$V^{\prime} \mathrm{O}_{2} / W$ & 0.82 & $<0.01$ & 0.61 & $<0.01$ \\
\hline$V_{E}^{\prime}$ & 0.6 & $<0.01$ & 0.52 & $<0.05$ \\
\hline$V^{\prime}{ }_{E}^{\prime} / V_{\mathrm{O}_{2}}^{\prime}$ & -0.76 & $<0.01$ & -0.68 & $<0.01$ \\
\hline$V^{\prime}{ }_{E}^{\prime} / V^{\prime}{ }_{\mathrm{CO}_{2}}$ & -0.81 & $<0.01$ & -0.74 & $<0.01$ \\
\hline$\Delta \mathrm{IC}$ & 0.77 & $<0.01$ & 0.16 & 0.49 \\
\hline mBorg scale dyspnoea & -0.75 & $<0.01$ & -0.15 & 0.5 \\
\hline mBorg scale leg fatigue & 0.22 & 0.15 & 0.28 & 0.18 \\
\hline
\end{tabular}

BMI: body mass index; QMS: quadriceps muscle strength; IC: inspiratory capacity; FVC: forced vital capacity; $\mathrm{FEV}_{1}$ : forced expiratory volume in $1 \mathrm{~s}$; MIP: maximum inspiratory pressure; $V_{\mathrm{O}_{2}}$ : oxygen uptake; $V_{\mathrm{O}_{2}}^{\prime} / W$ : oxygen uptake/weight; $V_{\mathrm{E}}^{\prime}$ : minute ventilation; $V^{\prime} \mathrm{CO}_{2}$ : carbon dioxide output; IC: inspiratory capacity.

physical and ventilatory capacity, as well as increased dyspnoea during exercise in COPD patients. The reduction in diaphragmatic mobility in COPD patients is similar to the reduction in mobility reported in previous studies $[24,25]$.

Ultrasonography has also been used to assess the length and thickness of the zone of apposition of the diaphragm against the rib cage [17]. Diaphragmatic thickness (Tdi) is measured by placing a high-frequency linear probe at the level of the zone of apposition, while diaphragmatic excursion is measured by placing a curvilinear probe in the subcostal region and recording diaphragmatic movements in the M-mode. In healthy participants at rest, the intra- and interobserver reliability of Tdi measurements

a)

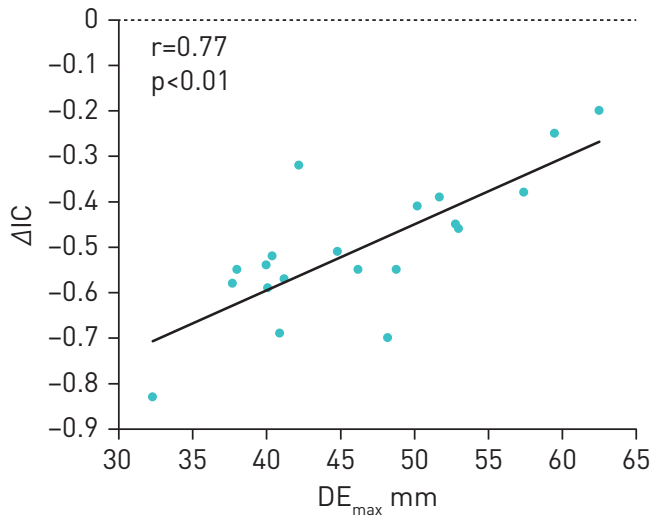

b)

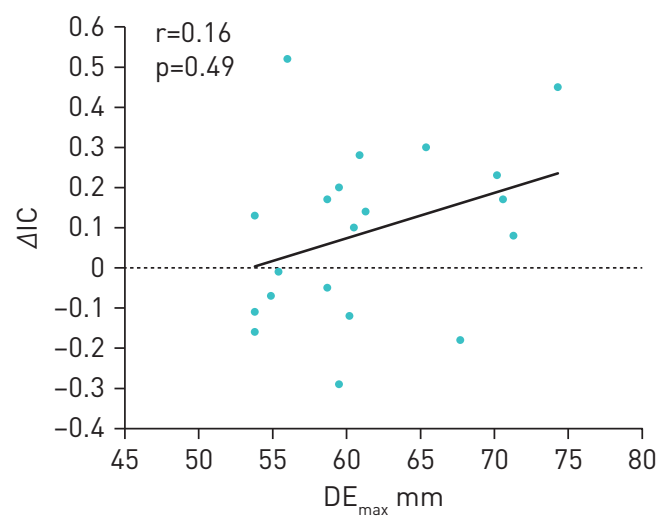

FIGURE 3 Correlation between maximum diaphragmatic excursion $\left(D E_{\max }\right)$ and peak change in inspiratory capacity $(\Delta I C)$ in a) patients with COPD $(n=20)$ and b) healthy participants $(n=20)$. $\Delta I C$, which reflects dynamic lung hyperinflation, was significantly positively correlated with $\mathrm{DE}_{\max }$ in patients with COPD, while $\triangle \mathrm{IC}$ was not correlated with $\mathrm{DE}_{\max }$ in control participants. 
a)

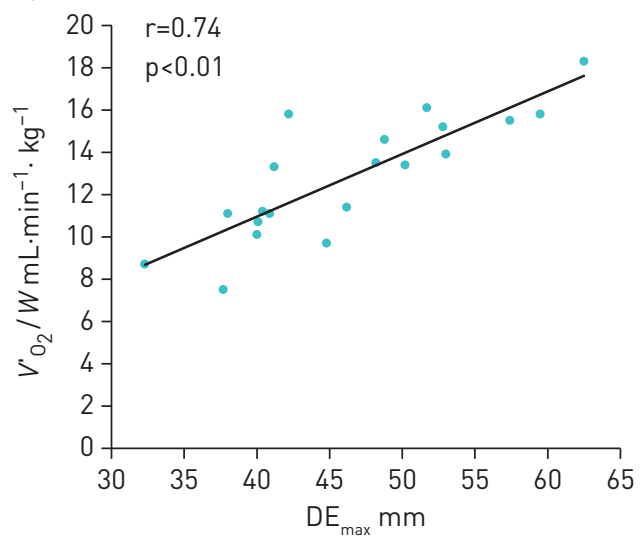

b)

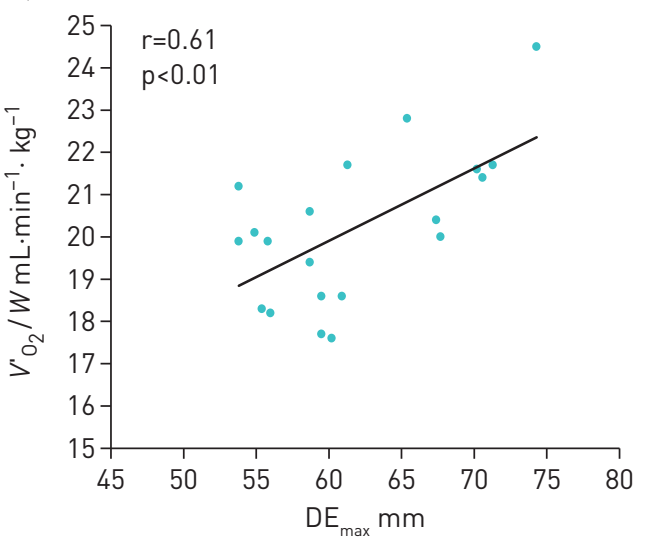

FIGURE 4 Correlation between maximum diaphragmatic excursion $\left(D E_{\max }\right)$ and peak oxygen uptake $\left(V^{\prime}{ }_{\mathrm{O}_{2}}\right) /$ weight $(W)$ in a) patients with $\operatorname{COPD}(n=20)$ and b) healthy participants $(n=20)$. $D E_{\max }$ was significantly positively correlated with $V^{\prime}{ }_{O_{2}} / W$ in both patients with $\mathrm{COPD}$ and healthy participants.

are high [26-29], and ultrasonography estimates of Tdi are correlated with direct anatomical measurements [29]. The temporal evolution of Tdi in patients was related to the change in VC in the patients with recovery of diaphragmatic function, and Tdi can also be used to monitor the evolution of diaphragmatic weakness [30]. However, ultrasonographic measurements of diaphragmatic thickening explain only one-third (or less) of the variability in inspiratory effort [9, 10, 21]. Furthermore, the evaluation of Tdi is difficult to perform in patients with severe COPD, because the length of the zone of apposition is shorter in COPD patients than in control patients [31]. On the other hand, ultrasonographic measurements of excursions of the right hemidiaphragm have shown high intra- and interobserver reliability [32]. Diaphragmatic excursions are sensitive to changes in respiratory patterns [33], are related to the volume-generating capacity of the diaphragm (measured by VC) following abdominal surgery [34], and have been used to identify diaphragmatic weakness in the setting of the acute exacerbation of COPD [35].

In this study, IC decreased during CPET, and $\mathrm{DE}_{\max }$ was correlated with the change in the IC of COPD patients. DLH occurs when respiration is accelerated by exercise or exertion, and IC decreases in COPD patients. Normally, tidal volume (TV) increases during exercise, increasing the necessary $V^{\prime}{ }_{\mathrm{O}_{2}}$; but in COPD, TV does not increase because of the decreased IC, and respirations become shallow and rapid [36]. Hyperinflation of the lungs with consequent reduction in IC has been convincingly linked to the degree of breathlessness (dyspnoea) experienced by patients with COPD during physical activity. Moreover, the therapeutic reversal of lung hyperinflation with improvement in IC has been shown to be associated with improvements in the intensity of dyspnoea and exercise endurance [37]. Ultrasonographic assessment of the diaphragm can help identify the subpopulation of COPD patients with dysfunctional diaphragms and the consequent changes in ventilatory mechanics.

There are limitations to this study. This study was conducted at a single centre on a relatively small number of participants. Therefore, this study might have been underpowered for some of the statistical analyses. However, the number of participants was sufficient for the primary outcome, which was a comparison between the mean $\mathrm{DE}_{\max }$ values of the COPD patients and control participants. We also did not measure the residual volume and FRC of the control participants; therefore, we could not compare between these parameters in the two study groups.

In conclusion, the diaphragmatic mobility of COPD patients was reduced compared with the control participants. Diaphragmatic mobility was correlated with exercise tolerance in both the COPD patients and control participants. Reduced mobility of the diaphragm was related to decreased exercise capacity and increased dyspnoea due to dynamic lung hyperinflation in COPD patients. The assessment of diaphragmatic mobility in patients with COPD could further the understanding of their limitations in daily activities as well as inform those medical decisions related to therapeutic strategies.

Conflict of interest: M. Shiraishi has nothing to disclose. Y. Higashimoto has nothing to disclose. R. Sugiya has nothing to disclose. H. Mizusawa has nothing to disclose. Y. Takeda has nothing to disclose. S. Fujita has nothing to disclose. O. Nishiyama has nothing to disclose. S. Kudo has nothing to disclose. T. Kimura has nothing to disclose. Y. Chiba has nothing to disclose. K. Fukuda has nothing to disclose. Y. Tohda reports grants from Kyorin Pharmaceutical, MeijiSeika Pharma, Boehringer Ingelheim, Teijin Pharma, DaiichiSankyo, Astellas andPearl outside the submitted work. 


\section{References}

1 Gagnon P, Guenette JA, Langer D, et al. Pathogenesis of hyperinflation in chronic obstructive pulmonary disease. Int J COPD 2014; 9: 187-201.

2 Calverley PMA, Koulouris NG. Flow limitation and dynamic hyperinflation: key concepts in modern respiratory physiology. Eur Respir J 2005; 25: 186-199.

3 Khirani S, Polese G, Aliverti A, et al. On-line monitoring of lung mechanics during spontaneous breathing: a physiological study. Respir Med 2010; 104: 463-471.

4 Cooper CB. The connection between chronic obstructive pulmonary disease symptoms and hyperinflation and its impact on exercise and function. Am J Med 2006; 119: 21-31.

5 Laveneziana $\mathrm{P}$, Albuquerque A, Aliverti A, et al. ERS statement on respiratory muscle testing at rest and during exercise. Eur Respir J 2019; 53: 1801214.

6 Boussuges A, Gole Y, Blanc P. Diaphragmatic motion studied by M-mode ultrasonography. Chest 2009; 135: 391-400.

7 Testa A, Soldati G, Giannuzzi R, et al. Ultrasound M-mode assessment of diaphragmatic kinetics by anterior transverse scanning in healthy subjects. Ultrasound Med Biol 2011; 37: 44-52.

8 Ueki J, De Bruin PF, Pride NB. In vivo assessment of diaphragm contraction by ultrasound in normal subjects Thorax 1995; 50: 1157-1161.

9 Vivier E, Dessap AM, Dimassi S, et al. Diaphragm ultrasonography to estimate the work of breathing during non-invasive ventilation. Intensive Care Med 2012; 38: 796-803.

10 Goligher EC, Laghi F, Detsky ME, et al. Erratum to: measuring diaphragm thickness with ultrasound in mechanically ventilated patients: feasibility, reproducibility and validity [Intensive Care Medicine, DOI 10.1007/ s00134-015-3687-3]. Intensive Care Med 2015; 41: 734.

11 Kim WY, Suh HJ, Hong SB, et al. Diaphragm dysfunction assessed by ultrasonography: Influence on weaning from mechanical ventilation. Crit Care Med 2011; 39: 2627-2630.

12 dos SantosYamaguti WP, Paulin E, Salge JM, et al. Diaphragmatic dysfunction and mortality in patients with COPD. J Bras Pneumol 2009; 35: 1174-1181.

13 Borg GA. Psychophysical bases of perceived exertion. Med Sci Sport Exerc 1982; 14: 377-381.

14 Satake M, Shioya T, Takahashi H, et al. Dynamic hyperinflation and dyspnea during the 6-minute walk test in stable chronic obstructive pulmonary disease patients. Int J Chron Obstruct Pulmon Dis 2015; 7: 153.

15 O'Donnell DE. Hyperinflation, dyspnea, and exercise intolerance in chronic obstructive pulmonary disease. Proc Am Thorac Soc 2006; 3: 180-184.

16 Graham BL, Steenbruggen I, Barjaktarevic IZ, et al. Standardization of spirometry 2019 update an official American Thoracic Society and European Respiratory Society technical statement. Am J Respir Crit Care Med; 2019: E70-E88.

17 Gibson GJ, Whitelaw W, Siafakas N, et al. ATS/ERS Statement on respiratory muscle testing. Am J Respir Crit Care Med 2002; 166: 518-624.

18 Lerolle N, Guérot E, Dimassi S, et al. Ultrasonographic diagnostic criterion for severe diaphragmatic dysfunction after cardiac surgery. Chest 2009; 135: 401-407.

19 Vassilakopoulos T, Petrof BJ. Ventilator-induced diaphragmatic dysfunction. Am J Respir Crit Care Med 2004; 169: 336-341.

20 Tobin MJ, Laghi F, Brochard L. Role of the respiratory muscles in acute respiratory failure of COPD: lessons from weaning failure. J Appl Physiol 2009; 107: 962-970.

21 Llamas-Álvarez AM, Tenza-Lozano EM, Latour-Pérez J. Diaphragm and lung ultrasound to predict weaning outcome: systematic review and meta-analysis. Chest 2017; 152: 1140-1150.

22 Dinino E, Gartman EJ, Sethi JM, et al. Diaphragm ultrasound as a predictor of successful extubation from mechanical ventilation. Thorax 2014; 69: 423-427.

23 Paulin E, Yamaguti WPS, Chammas MC, et al. Influence of diaphragmatic mobility on exercise tolerance and dyspnea in patients with COPD. Respir Med 2007; 101: 2113-2118.

24 Scheibe N, Sosnowski N, Pinkhasik A, et al. Sonographic evaluation of diaphragmatic dysfunction in COPD patients. Int J COPD 2010; 10: 1925-1930.

25 Iwasawa $\mathrm{T}$, Takahashi $\mathrm{H}$, Ogura $\mathrm{T}$, et al. Influence of the distribution of emphysema on diaphragmatic motion in patients with chronic obstructive pulmonary disease. Jpn J Radiol 2011; 29: 256-264.

26 O’Donnell DE, Lam M, Webb KA. Measurement of symptoms, lung hyperinflation, and endurance during exercise in chronic obstructive pulmonary disease. Am J Respir Crit Care Med 1998; 158: 1557-1565.

27 Enright S, Chatham K, Ionescu AA, et al. The influence of body composition on respiratory muscle, lung function and diaphragm thickness in adults with cystic fibrosis. J Cyst Fibros 2007; 6: 384-390.

28 Cohn D, Benditt JO, Eveloff S, et al. Diaphragm thickening during inspiration. J Appl Physiol 1997; 83: 291-296.

29 Baldwin CE, Paratz JD, Bersten AD. Diaphragm and peripheral muscle thickness on ultrasound: Intra-rater reliability and variability of a methodology using non-standard recumbent positions. Respirology 2011; 16: 1136-1143.

30 Summerhill EM, El-Sameed YA, Glidden TJ, et al. Monitoring recovery from diaphragm paralysis with ultrasound. Chest 2008; 133: 737-743.

31 McKenzie DK, Butler JE, Gandevia SC. Respiratory muscle function and activation in chronic obstructive pulmonary disease. J Appl Physiol 2009; 107: 621-629.

32 Laveneziana $\mathrm{P}$, Albuquerque A, Aliverti A, et al. ERS statement on respiratory muscle testing at rest and during exercise. Eur Respir J 2019; 53: 1801214

33 Jones AYM, Ngai SPC, Ying MTC, et al. Sonographic evaluation of diaphragmatic function during breathing control. Physiother Theory Pract 2017; 33: 560-567.

34 Kim SH, Na S, Choi JS, et al. An evaluation of diaphragmatic movement by M-mode sonography as a predictor of pulmonary dysfunction after upper abdominal surgery. Anesth Analg 2010; 110: 1349-1354.

35 Numis FG, Morelli L, Bosso G, et al. Diaphragmatic motility assessment in COPD exacerbation, early detection of non-invasive mechanical ventilation failure: a pilot study. Crit Ultrasound J 2014; 6: A6.

36 O'Donnell DE, Hamilton AL, Webb KA. Sensory-mechanical relationships during high-intensity, constant-workrate exercise in COPD. J Appl Physiol 2006; 101: 1025-1035.

37 O'Donnell DE, Flüge T, Gerken F, et al. Effects of tiotropium on lung hyperinflation, dyspnoea and exercise tolerance in COPD. Eur Respir J 2004; 23: 832-840. 